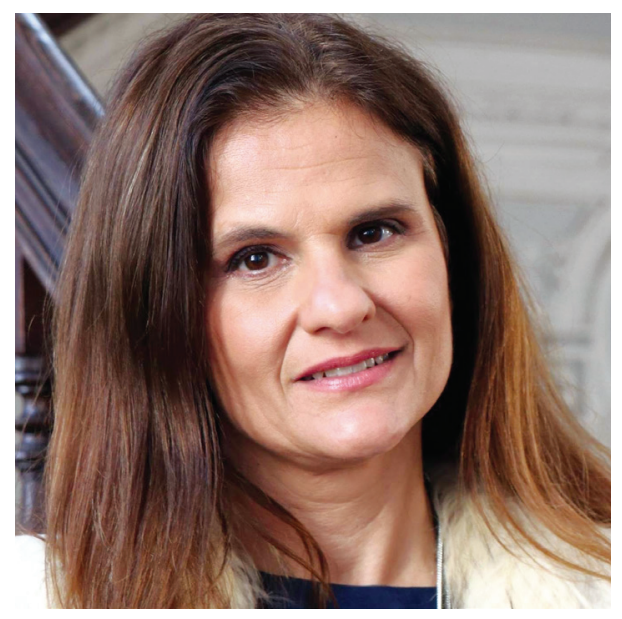

\title{
Tendências em Saúde
}

\section{Healthcare Trends}

Anabela Possidónio ${ }^{1}$

É com enorme satisfação que escrevo o editorial da Gazeta Médica. À semelhança do que vem acontecendo, neste número poderão encontrar artigos e casos clínicos que abarcam várias áreas do conhecimento médico-cirúrgico.

Tendo em consideração que entramos numa nova década, gostaria de dedicar este artigo às novas tendências na área da saúde sendo que, pela sua importância, não poderia deixar de falar em tecnologia. Contudo, sendo a saúde estruturante ao que nos define como pessoas, não poderei deixar de fora um tema tão importante como o relacionamento médico-paciente.

Do lado da tecnologia temos assistido a uma evolução enorme, que transformou a forma como nos relacionamos com o ambiente em que vivemos. Desde questões tão simples como fazer compras online, transferir dinheiro ou comunicar com pessoas em qualquer parte do mundo, a tecnologia permitiu grandes avanços na ciência. Apenas a título de exemplo, quando pensamos em saúde, os pacientes passaram a ter acesso a técnicas avançadas de diagnóstico, a cirurgia minimamente invasiva e a tratamentos revolucionários, que transformaram a forma como se prestam cuidados de saúde.

Olhando para o futuro, segundo um relatório da McKinsey, ${ }^{1}$ as nove tendências tecnológicas que maior impacto já estão e continuarão a ter no sector da saúde são:

1. Utilização de dispositivos que monitorizam os parâmetros de saúde, administram a terapêutica de forma autónoma, ao mesmo tempo que integram o paciente com os seus cuidadores e a comunidade onde se insere.

2. Implantação de elétrodos que podem atuar ao nível do sistema central e que permitem tratar várias doenças.

3. Medicina de precisão: prática médica focada na pessoa através do recurso a testes genéticos, identificação de biomarcadores e desenvolvimento de terapêutica personalizada.

4. Robótica: a nova geração de robots vai permitir o avanço da cirurgia minimamente invasiva, ao mesmo tempo que automatiza várias tarefas.

5. Impressão 3D: esta tecnologia permite a criação de estruturas a 3 dimensões, compostas por material biológico e industrial, potenciando a possibilidade da criação de próteses personalizadas, substituição de órgãos e dosagem de medicamentos de precisão.

6. Big data e analytics: a utilização de plataformas para recolher e partilhar dados, potencia a existência de uma enorme quantidade de informação que permitirá diagnósticos mais precisos e uma melhor definição de terapias. Neste contexto, é de salientar que a utilização de big data está ainda no começo, sendo que o potencial de se transversalizar, incluindo a recolha de dados psicológicos durante procedimentos, é enorme. 
7. Inteligência artificial: de mãos dadas com a tendência anterior, a tecnologia potencia a conversão de dados em decisões clínicas, garantindo que são encontradas as melhores soluções para o doente e para a produtividade clínica.

8. Blockchain: banco de dados que funciona como um livro de registros inviolável, o que permite transações mais seguras, a partilha de dados confidenciais de pacientes e a democratização do acesso aos dados.

9. Automatização robótica de processos: a automatização de tarefas rotineiras terá um enorme impacto na produtividade, ao permitirem que as pessoas se foquem no que verdadeiramente acrescenta valor.

Paralelamente ao avanço destas tecnologias, o sector da saúde está sujeito a novos desafios relacionados com o enveIhecimento da população, o que coloca uma enorme pressão no sistema. Nesse sentido é expectável que, tanto ao nível das políticas, como do comportamento das próprias pessoas o foco na prevenção aumente. Isso é exatamente o que um relatório da PWC² vem confirmar. Segundo este relatório em 2030 os pacientes vão focar-se cada vez mais na prevenção, procurando soluções que se integram com o seu dia-a-dia. Assim, paralelamente à existência de novas tecnologias temos também um paciente cada vez mais informado e participativo, o que vai colocar pressão no sistema e nos profissionais de saúde, antecipando-se que os médicos passem a ter um maior papel na prevenção, e que os Sistemas de Saúde criem as condições para uma partilha de dados segura, ao mesmo tempo que investem mais na prevenção.

\begin{tabular}{|c|c|c|c|c|c|c|c|c|c|}
\hline \multirow{3}{*}{$\begin{array}{l}\text { How national healthcare } \\
\text { budgets will shift by } \\
2030 \text { ( } 2018 \text { vs. } 2030)\end{array}$} & \multirow{3}{*}{$\begin{array}{l}\text { Total budget } \\
\text { in } 2030 \\
\text { (US } \$ \text { billions) }\end{array}$} & \multicolumn{5}{|c|}{ EU 5} & & \multicolumn{2}{|c|}{ Total budget (no 2018 data) } \\
\hline & & France & Germany & Italy & Spain & UK & US & China & India \\
\hline & & 380 & 570 & 250 & 180 & 330 & 4,170 & 3,390 & 870 \\
\hline \multirow{6}{*}{$\begin{array}{l}\text { Source: OECD data; The Lancet; } \\
\text { Strategy \& analysis }\end{array}$} & Diagnostics & $\int^{11}$ & & 4 & & & & 193 & 49 \\
\hline & Preventative care & & & & & & & $31 \subseteq$ & 82 \\
\hline & $\begin{array}{l}\text { Other (e.g., } \\
\text { digital health) }\end{array}$ & & 3 & & & & & 282 & 72 \\
\hline & $\begin{array}{l}\text { Government \& } \\
\text { health system }\end{array}$ & 5 & 14 & & & & -3 & 217 & 56 \\
\hline & Medication & -1 & -2 & -5 & -7 & & & 55 & 143 \\
\hline & $\begin{array}{l}\text { Care excl. } \\
\text { medication }\end{array}$ & 29 & -28 & 1 & & & -11 & & \\
\hline
\end{tabular}

Tendo em consideração este contexto, em que existe um maior foco na prevenção e no uso de soluções digitais, é importante referir a emergência de novos stakeholders. Empresas como a Google, a Apple ou a Amazon estão a fazer enormes investimentos em inovação na área da saúde, sendo que as empresas farmacêuticas estão também elas a reinventar-se. O mesmo acontece com a área seguradora, que terá que alterar o foco do tratamento da doença, para a componente de prevenção.

Para terminar, gostaria de referir que apesar de todas as vantagens do desenvolvimento tecnológico, as mesmas têm também contribuído para um maior isolamento das pessoas e o desenvolvimento de novas patologias e adições. Na realidade tendo em consideração que o ser humano é eminentemente social é expectável que a relação médico-paciente ganhe ainda mais importância.

Na realidade, a importância da relação tem sido alvo de análise e, segundo um estudo que relaciona outcomes como a relação médico-doente no tratamento da síndrome do intestino irritado, ${ }^{3}$ mostrou que uma relação baseada em afeto, atenção e confiança tinha resultados superiores em termos de outcomes.

Fica assim provado que, num contexto marcadamente tecnológico, o lado humanista da profissão ganha ainda mais relevância, sendo que comportamentos como empatia, capacidade de escuta, toque e aconselhamento serão fundamentais no futuro. ${ }^{4}$

1.Singhal S, Carlton S. The era of exponential improvement in healthcare? McKinsey \& Company: 2019 [consultado novembro 2019] Disponível em: https://www. mckinsey.com/industries/healthcare-systems-and-services/our-insights/the-era-of-exponential-improvement-in-healthcare.

2. Solbach T, Kremer M, Grünewald P, Ickerott D. Driving the future of health: How biopharma can defend and grow its business in an era of digitally enabled healthcare. PwC network; 2019 [consultado novembro 2019] Disponível em: https://www.strategyand.pwc.com/gx/en/insights/2019/future-of-health.html.

3. Kaptchuk TJ, Kelley JM, Conboy LA, et al. Components of placebo effect: Randomised controlled trial in patients with irritable bowel syndrome. BMJ. 2008;336:9991003. doi: 10.1136/bmj.39524.439618.25.

4. Johnston SC. Anticipating and training the physician of the future: the importance of caring in an age of artificial intelligence. Acad Med. 2018;93:1105-6. doi: 10.1097/ACM.0000000000002175. 